Pacific Journal of Mathematic 


\section{A CHARACTERIZATION OF RIEMANN ALGEBRAS}

\section{BRUNo KRAMM}

A topological algebra $\mathscr{A}$ is called Riemann algebra if it is topologically isomorphic to the Fréchet algebra $O(R)$ of all holomorphic functions on some Riemann surface $R$.

One obtains a characterization of Riemann algebras by a theorem of $R$. L. Carpenter and the Oka-Weil-Cartan theorem; we show that: a uniform Fréchet algebra $\mathscr{A}$ whose spectrum is locally compact and connected, is a Riemann algebra if and only if every closed maximal ideal is principal.

1. Let $R$ be a Riemann surface and $\mathscr{O}(R)$ that algebra of all holomorphic functions on $R . \mathscr{O}(R)$ is a uniform Fréchet algebra, if it is endowed with the topology of uniform convergence on compact sets of $R$. A topological algebra $\mathscr{A}$ which is topologically isomorphic to $\mathcal{O}(R)$, is called a Riemann algebra.

If $R$ is compact, one obtains the trivial Riemann algebra $C$.

In $1953 \mathrm{~S}$. Kakutani posed the problem of characterizing Riemann algebras by intrinsic properties. The most far reaching result is due to I. Richards [9], who considers algebraic properties only. More natural conditions are obtained if one considers topologically algebraic properties. Some special results are found in R. F. Arens [1], F. T. Birtel [3], I. Kra [8], R. L. Carpenter [5]; a summary, in a sense, is provided by I. Richards' paper [10]. This present paper is written in a selfcontained way.

In his paper [4] R. L. Carpenter, using earlier work of A. Gleason [7], proved the following-here cited with a slight modification.

THEOREM. Let $\mathscr{A}$ be a uniform Fréchet algebra whose spectrum s. is locally compact and connected and does not consist of a singleton. If every closed maximal ideal in $\mathscr{A}$ is principal, then s.A can be given the structure of a Riemann surface in such a way that $A$ is topologically isomorphic to a closed subalgebra of $\mathcal{O}(\boldsymbol{s} \mathscr{A})$. Furthermore $\mathscr{A}$ contains local coordinates for every point in s.A.

In fact, we show that $\mathscr{A}$ is even topologically isomorphic to $\mathscr{O}(\boldsymbol{s} \mathscr{A})$ under the above hypotheses.

2. Let us fix some notations first. 
A Fréchet algebra ( $F$-algebra) is a commutative, locally convex, complete algebra over the complex field $C$ with unit whose topology is generated by a countable number of semi-norms.

Now let $\mathscr{A}$ be a $F$-algebra. By s $\mathscr{A}$ we denote the spectrum of $\mathscr{A}$, the set of all nontrivial continuous $C$-algebra homomorphisms $f: \mathscr{A} \rightarrow C$; as usual, it is given the Gelfand topology (=weak -* topology).

The Gelfand representation. Let $\mathscr{C}(s \mathscr{A})$ denote the space of all continuous functions on $\boldsymbol{s} \mathscr{A}$, endowed with the compact open topology. Then the standard Gelfand representation

$$
G: \mathscr{A} \longrightarrow \mathscr{C}(s \mathscr{A}), \quad a \longmapsto \hat{a}
$$

given by setting $\hat{a}(\boldsymbol{f}):=\boldsymbol{f}(a)$ for $a \in \mathscr{A}, \boldsymbol{f} \in \boldsymbol{s} \mathscr{A}$, is a continuous $\boldsymbol{C}$ algebra-homomorphism.

Call $\mathscr{A}$ a uniform Fréchet algebra ( $u F$-algebra), if the Gelfand representation $G$ induces a topological isomorphism of $\mathscr{A}$ onto a closed subalgebra $G(\mathscr{A}) \subset \mathscr{C}(s \mathscr{A})$.

Let $K \subset \boldsymbol{s} \mathscr{A}$ be a compact set. For $a \in \mathscr{A}$ we denote the $K$-sup norm as usual.

$$
\|a\|_{K}:=\sup _{f \in K}|\hat{a}(f)| .
$$

By $\mathscr{A}_{K}$ we denote the separated completion of $\mathscr{A}$ under the seminorm $\|\cdot\|_{K}$. It is well known that a $u F$-algebra $\mathscr{A}$ can be represented as an inverse limit of countably many uniform Banach algebras

$$
\mathscr{A}=\lim _{\leftarrow} \mathscr{A}_{K_{n}},
$$

where an appropriate sequence $\cdots \subset K_{n} \subset K_{n+1} \subset \cdots$ of compact subsets exhausts $s \mathscr{A}$ such that any compact $K \subset \boldsymbol{s} \mathscr{A}$ is contained in some $K_{n}$.

It is well known (e.g. cf. [6] p. 377f.) that every Riemann algebra $\mathcal{O}(R)$ is a $u F$-algebra whose Gelfand space is topologically equivalent to $R$. The following gives a simple characterization of Riemann algebras.

THeOREm. Let $\mathscr{A} \neq \boldsymbol{C}$ be a $u F$-algebra such that s. $\mathscr{A}$ is locally compact and connected. Then the following statements are equivalent: 

(i) $\mathscr{A}$ is a Riemann algebra;
(ii) every closed maxmal ideal in $\mathscr{A}$ is principal;
(iii) every closed ideal in $\mathscr{A}$ is principal.

Proof. The implication (i) $\Rightarrow$ (iii) follows e.g. from O. Forster [6], Satz 5.2. The implication (iii) $\Rightarrow$ (ii) is trivial. New we prove (ii) $\Rightarrow$ (i) $)^{1}$.

Carpenter's theorem states in particular: s. $\mathscr{A}$ can be given the structure of a Riemann surface by coordinates which are the Gelfand transforms of certain elements of $\mathscr{A}$, such that $G(\mathscr{A})$ is a closed subalgebra of $\mathcal{O}(\boldsymbol{s} \mathscr{A})$.

Now we want to prove that $G(\mathscr{A})=\mathscr{O}(\boldsymbol{s} \mathscr{A})$. We will do this by means of the Oka-Weil-Cartan theorem (cf. [2], p. 145) which we state here, together with the necessary definitions. Recall that $s \mathscr{A}$ is a Riemann surface, and $G(\mathscr{A})$ is an algebra of holomorphic func-

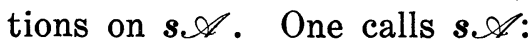
set

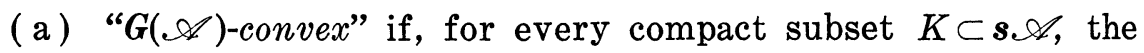

$$
\hat{K}=\left\{\boldsymbol{f} \in \boldsymbol{s} \mathscr{A}|| \hat{a}(\boldsymbol{f}) \mid \leqq\|a\|_{K} \text { for all } \hat{a} \in \boldsymbol{G}(\mathscr{A})\right\}
$$

is also compact;

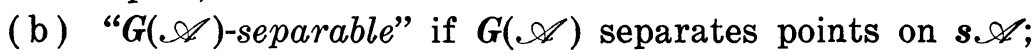

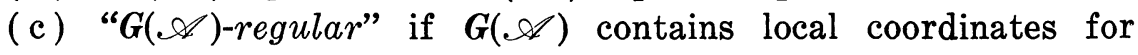
every point of $s \mathscr{A}$.

The Oka-Weil-Cartan theorem states that for any Stein manifold (and hence in particular for any noncompact Riemann surface), the conditions (a), (b), (c) imply that the algebra $G(\mathscr{A})$ is dense in $O(s \mathscr{A})$.

Thus we wish to show that $s \mathscr{A}$ is $G(\mathscr{A})$-convex, $G(\mathscr{A})$-separable, and $G(\mathscr{A})$-regular.

$G(\mathscr{A})$-separable. This is trivial, since by definition the algebra

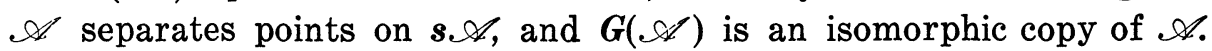
$G(\mathscr{A})$-regular. The existence of local coordinates is part of Carpenter's theorem.

$G(\mathscr{A})$-convex. This follows from the fact that $\mathscr{A}$ is a $u F$ algebra and from Tychonov's theorem. Take any compact set $K \subset \boldsymbol{s} \mathscr{A}$. We need to show that its $\boldsymbol{G}(\mathscr{A})$-convex hull $\hat{K}$ defined in (a) above is also compact. The restriction map $G(\mathscr{A}) \rightarrow G(\mathscr{A})_{K}$ has dense image and therefore, the canonic map $s \mathscr{A}_{K} \rightarrow \boldsymbol{s} \mathscr{A}$ is injective;

1 There is a different, more complicated proof of the main theorem which uses the functional calculus for $B$-algebras instead of the Oka-Weil-Cartan theorem. 
it is even a homomorphic embedding, as a direct calculation with a subbasis of the weak-* topology of s.

Now it is easily seen that $\hat{K}$ coincides with $\boldsymbol{s} \mathscr{A}_{K}$. Since $\mathscr{A}_{K}$ is a commutative Banach algebra with unit, it follows from Tychonov's theorem that $\mathscr{A}_{K}$ has compact spectrum. Thus $\hat{K}$ is compact, and the $G(\mathscr{A})$-convexity is proved.

Now the Oka-Weil-Cartan theorem implies that $G(\mathscr{A})$ is a dense subalgebra of $\mathcal{O}(\boldsymbol{s} \mathscr{A})$. Since $\mathscr{A}$ is complete and topologically isomorphic to $G(\mathscr{A})$, we conclude that $G(\mathscr{A})=\mathscr{O}(\boldsymbol{s} \mathscr{A})$, as desired.

3. We illustrate the proof of our theorem by three examples. Let $C^{*}:=C-\{0\}$. Then $\mathscr{A}_{1}:=\mathscr{O}(\boldsymbol{C})$ is a (closed) $u F$-subalgebra of $\mathcal{O}\left(C^{*}\right) . \quad C^{*}$ is $\mathscr{A}_{1}$-separable and $\mathscr{A}_{1}$-regular but not $\mathscr{A}_{1}$-convex, and indeed $\mathscr{A}_{1} \neq \mathscr{O}\left(C^{*}\right)$.

It is easily seen that the algebra $\mathscr{A}_{2}$ of all holomorphic functions on the analytic set

$$
\left\{(x, y) \in C^{2} \mid x^{3}-y^{2}=0\right\} \quad \text { (Neil's parabola) }
$$

may be identified algebraically and topologically with the uniform closure of $C\left[z^{2}, z^{3}\right]$ in $\mathscr{O}(C) . \quad C$ ist $\mathscr{A}_{2}$-separable and $\mathscr{A}_{2}$-convex but not $\mathscr{A}_{2}$-regular. For one cannot find in $\mathscr{A}_{2}$ any local coordinate for a neighbourhood of $0 \in C$ which is equivalent to $z \in \mathcal{O}(C)$. In fact, the maximal ideal in $\mathscr{A}_{2}$ correspondent to $\mathscr{O} \in C$ is not principal, and therefore $\mathscr{A}_{2}$ is not a Riemann algebra.

The uniform closure of $C\left[z^{2}, 1 / z^{2}\right]$ in $\mathscr{O}\left(C^{*}\right)$ provides an example of a $u F$-subalgebra $\mathscr{A}_{3}$ such that $C^{*}$ is $\mathscr{A}_{3}$-convex and $\mathscr{A}_{3}$-regular but not $\mathscr{A}_{3}$-separable.

It can happen that a Riemann algebra contains a properly closed subalgebra which can be mapped topologically isomorphic onto the former algebra. For example, take the above algebras $\mathscr{A}_{3} \subset \mathcal{O}\left(C^{*}\right)$. The map $\mathscr{O}\left(C^{*}\right) \rightarrow \mathscr{A}_{3}$ induced by $z \mapsto z^{2}$, is a topologic isomorphism, by the open mapping theorem for Fréchet spaces. The hence homeomorphic spectra are linked as a twosheeted covering, by the adjoint spectral map of the inclusion map $\mathscr{A}_{3} \subset \mathcal{O}\left(C^{*}\right)$.

4. We assume in this section that all $u F$-algebras under consideration have locally compact and connected spectrum. "Generators" for algebras are understood to be topological generators. Call a Riemann algebra planar, if its associated Riemann surface can be realized as a domain in the complex plane. Then the above theorem and Runge's approximation theorem yield the

CoRollary. A Riemann algebra is planar if and only if it is 
a singly rationally generated $u F$-algebra, whose closed maximal ideals are principal.

Finally, we note two reformulations of classic function theory in the language of $u F$-algebras.

\section{Proposition.}

(1) There exist two and only two singly generated uF-algebras whose closed maximal ideals are principal (modulo topological isomorphism).

(2) Every uF-algebra such that every closed maximal ideal is principal, can be generated by three elements.

Proof. (1) Use Riemann's mapping theorem.

(2) Use the embedding theorem for Riemann surfaces.

ACKNOWLEDGMENT. The author is indebted to Otto Forster for a hint as to simplification, and he wishes to thank the referee for a lot of (not only) stylistic improvements.

\section{REFERENCES}

1. R. F. Arens, Dense inverse limit rings, Michigan Math. J., 5 (1958), 169-182.

2. H. Behnke and P. Thullen, Theorie der Funktionen mehrerer komplexer Veränderlichen, Springer-Verlag, Berlin-Heidelberg-New York, 1970.

3. F. T. Birtel, Singly-generated Liouville F-algebras, Michigan Math. J., 11 (1964), 89-94.

4. R. L. Carpenter, Principal ideals in F-algebras, Pacific J. Math., 35 (1970), 559-563.

$5 . \quad$ Singly generated homogeneous $F$-algebras, Trans. Amer. Math. Soc., 150 (1970), 457-468.

6. O. Forster, Zur Theorie der Steinschen Algebren und Moduln, Math. Zeitschr., 97 (1967), 376-405.

7. A. Gleason, Finitely generated ideals in Banach algebras, J. Math. Mech., 13 (1964), 125-132.

8. I. Kra, On the ring of holomorphic functions on an open Riemann surface, Trans. Amer. Math. Soc., 132 (1968), 231-244.

9. I. Richards, A criterion for rings of analytic functions, Trans. Amer. Math. Soc., 128 (1967), 523-530.

10. — Axioms for analytic functions, Advances in Math., 5 (1971), 311-338.

Received January 28, 1976 and in revised form June 15, 1976.

Fachbereich Mathematik/Physik

DER UNIVERSITÄT BAYREUTH

POSTFACH 3008

8580 BAYREUTH

Germany 



\section{PACIFIC JOURNAL OF MATHEMATICS}

\section{EDITORS}

RICHARD ARENS (Managing Editor)

University of California

Los Angeles, California 90024

\section{R. A. Beaumont}

University of Washington

Seattle, Washington 98105
J. DugundjI

Department of Mathematics

University of Southern California

Los Angeles, California 90007

D. Gilbarg and J. Milgram

Stanford University

Stanford, California 94305

\section{ASSOCIATE EDITORS}
E. F. BECKENBACH
B. H. NeumanN
F. WOLF
K. YosHIDA

\section{SUPPORTING INSTITUTIONS}

\author{
UNIVERSITY OF BRITISH COLUMBIA \\ CALIFORNIA INSTITUTE OF TECHNOLOGY \\ UNIVERSITY OF CALIFORNIA \\ MONTANA STATE UNIVERSITY \\ UNIVERSITY OF NEVADA \\ NEW MEXICO STATE UNIVERSITY \\ OREGON STATE UNIVERSITY \\ UNIVERSITY OF OREGON \\ OSAKA UNIVERSITY
}

\author{
UNIVERSITY OF SOUTHERN CALIFORNIA \\ STANFORD UNIVERSITY \\ UNIVERSITY OF HAWAII \\ UNIVERSITY OF TOKYO \\ UNIVERSITY OF UTAH \\ WASHINGTON STATE UNIVERSITY \\ UNIVERSITY OF WASHINGTON \\ AMERICAN MATHEMATICAL SOCIETY
}

The Supporting Institutions listed above contribute to the cost of publication of this Journal, but they are not owners or publishers and have no responsibility for its content or policies.

Mathematical papers intended for publication in the Pacific Journal of Mathematics should be in typed form or offset-reproduced, (not dittoed), double spaced with large margins. Please do not use built up fractions in the text of your manuscript. You may however, use them in the displayed equations. Underline Greek letters in red, German in green, and script in blue. The first paragraph or two must be capable of being used separately as a synopsis of the entire paper. Items of the bibliography should not be cited there unless absolutely necessary, in which case they must be identified by author and Journal, rather than by item number. Manuscripts, in triplicate, may be sent to any one of the editors. Please classify according to the scheme of Math. Reviews, Index to Vol. 39. All other communications should be addressed to the managing editor, or Elaine Barth, University of California, Los Angeles, California, 90024.

The Pacific Journal of Mathematics expects the author's institution to pay page charges, and reserves the right to delay publication for nonpayment of charges in case of financial emergency.

100 reprints are provided free for each article, only if page charges have been substantially paid. Additional copies may be obtained at cost in multiples of 50 .

The Pacific Journal of Mathematics is issued monthly as of January 1966. Regular subscription rate: $\$ 72.00$ a year (6 Vols., 12 issues). Special rate: $\$ 36.00$ a year to individual members of supporting institutions.

Subscriptions, orders for back numbers, and changes of address should be sent to Pacific Journal of Mathematics, 103 Highland Boulevard, Berkeley, California, 94708.

PUBLISHED BY PACIFIC JOURNAL OF MATHEMATICS, A NON-PROFIT CORPORATION

Printed at Kokusai Bunken Insatsusha (International Academic Printing Co., Ltd.), 8-8, 3-chome, Takadanobaba, Shinjuku-ku, Tokyo 160, Japan. 


\section{Pacific Journal of Mathematics \\ Vol. 65, No. $2 \quad$ October, 1976}

Andrew Adler, Weak homomorphisms and invariants: an example .......... 293

Howard Anton and William J. Pervin, Separation axioms and metric-like

functions ............................................. 299

Ron C. Blei, Sidon partitions and p-Sidon sets .................... 307

T. J. Cheatham and J. R. Smith, Regular and semisimple modules ........... 315

Charles Edward Cleaver, Packing spheres in Orlicz spaces .............. 325

Le Baron O. Ferguson and Michael D. Rusk, Korovkin sets for an operator on a

space of continuous functions ............................. 337

Rudolf Fritsch, An approximation theorem for maps into Kan fibrations ....... 347

David Sexton Gilliam, Geometry and the Radon-Nikodym theorem in strict

Mackey convergence spaces .................................

William Hery, Maximal ideals in algebras of topological algebra valued

functions ...................................... 365

Alan Hopenwasser, The radical of a reflexive operator algebra ........... 375

Bruno Kramm, A characterization of Riemann algebras................. 393

Peter K. F. Kuhfittig, Fixed points of locally contractive and nonexpansive

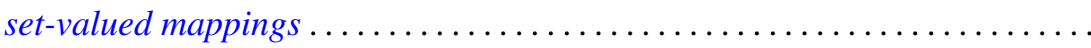

Stephen Allan McGrath, On almost everywhere convergence of Abel means of

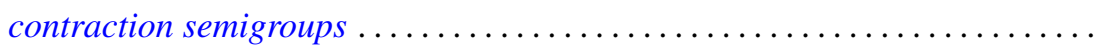

Edward Peter Merkes and Marion Wetzel, A geometric characterization of

indeterminate moment sequences............................ 409

John C. Morgan, II, The absolute Baire property ................... 421

Eli Aaron Passow and John A. Roulier, Negative theorems on generalized convex approximation .................................... 437

Louis Jackson Ratliff, Jr., A theorem on prime divisors of zero and characterizations of unmixed local domains ..............

Ellen Elizabeth Reed, A class of $T_{1}$-compactifications................... 471

Maxwell Alexander Rosenlicht, On Liouville's theory of elementary

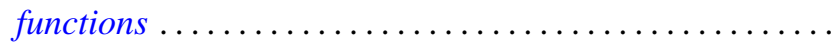

Arthur Argyle Sagle, Power-associative algebras and Riemannian

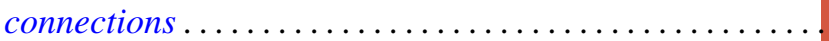

Chester Cornelius Seabury, On extending regular holomorphic maps from Stein manifolds...

Elias Sai Wan Shiu, Commutators and numerical ranges of powers of operators ...................................

Donald Mark Topkis, The structure of sublattices of the product of $n$ lattices ... 525

John Bason Wagoner, Delooping the continuous $K$-theory of a valuation

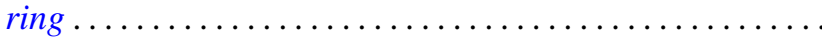

Ronson Joseph Warne, Standard regular semigroups...........

Anthony William Wickstead, The centraliser of $E \otimes_{\lambda} F \ldots$. 